\title{
Acúmulo de matéria seca e micronutrientes em mandioca consorciada com bananeira ${ }^{1}$
}

\author{
Heider Rodrigo Ferreira Silva², Vinicius Lopes Melo², \\ Dilermando Dourado Pacheco ${ }^{3}$, Ygho Jackson Muniz de Assis ${ }^{3}$, Hamilton dos Reis Sales ${ }^{3}$
}

\begin{abstract}
Dry matter and micronutrients accumulation in cassava intercropped with banana tree

Cassava is an important intercropping plant. However, there is little information on its dry matter accumulation and partitioning, as well as micronutrient demand, when it is intercropped with fruit trees. The study was conducted in Januária, Minas Gerais State, Brazil, in 2010-2011, aiming at evaluating the dry matter and micronutrients accumulation in cassava intercropped with irrigated banana tree. A randomized blocks design, with four replications, was used, with treatments consisting of 14 sampling periods, from sowing to harvest. At each sampling period, plants were classified as shoots (stems and leaves) and roots, for determining their dry matter and contents of $\mathrm{Cu}, \mathrm{Fe}, \mathrm{Mn}$ and $\mathrm{Zn}$. The dry matter and micronutrients accumulation fitted a sigmoidal growth pattern. The shoot dry matter accumulation increased up to 200 days after planting (DAP), stabilizing thereafter up to the end of the crop cycle. For roots, the dry matter accumulation was continuous up to the end of the cycle. From 250 DAP, roots became the main dry matter accumulation organ. Micronutrients accumulation in cassava plants occured in the following order: $\mathrm{Fe}>\mathrm{Zn}>\mathrm{Mn}>$ $\mathrm{Cu}$. It was concluded that the cultivation of cassava intercropped with banana tree is viable, provided there is a proper availability of micronutrients required by plants.
\end{abstract}

KEY-WORDS: Manihot esculenta Crantz.; Musa spp.; mineral balance.

\section{INTRODUÇÃO}

A mandioca é uma espécie perene, de propagação vegetativa e origem sul-americana, pertencente à família Euphorbiaceae, cultivada em todas as regiões do território nacional, sob diversas condições edafoclimáticas. Caracterizada pela produção de raízes e fécula, apresenta importância socioeconômica na região dos trópicos, sendo utilizada como fonte alimentar para humanos e animais, além da produção

\section{RESUMO}

A mandioca é uma importante cultura consorte. Entretanto, existem poucas informações sobre o acúmulo e partição de matéria seca na planta, bem como a demanda de micronutrientes, quando utilizada como espécie intercalar com frutíferas. O estudo foi conduzido em Januária (MG), em 20102011, com o objetivo de avaliar o acúmulo de matéria seca e micronutrientes em mandioca consorciada com bananeira irrigada. Utilizou-se delineamento de blocos ao acaso, com quatro repetições, considerando-se, como tratamentos, 14 épocas de coleta, do plantio até a colheita. Em cada coleta, as plantas foram separadas em parte aérea (caules e folhas) e raízes, para determinação da matéria seca e teores de $\mathrm{Cu}, \mathrm{Fe}, \mathrm{Mn}$ e $\mathrm{Zn}$. O acúmulo de matéria seca e micronutrientes seguiu padrão de crescimento sigmoidal. $\mathrm{O}$ acúmulo de matéria seca da parte aérea foi crescente até 200 dias após o plantio (DAP), estabilizandose, posteriormente, até o fim do ciclo de cultivo. Nas raízes, o acúmulo de matéria seca foi contínuo até o fim do ciclo. A partir de 250 DAP, as raízes foram o principal órgão de acúmulo de matéria seca na planta. Para o acúmulo de micronutrientes nas plantas de mandioca, a ordem foi a seguinte: $\mathrm{Fe}>\mathrm{Zn}>\mathrm{Mn}>$ $\mathrm{Cu}$. Concluiu-se que o cultivo de mandioca em consórcio com bananeira é viável, desde que haja adequada disponibilidade dos micronutrientes mais requeridos pelas plantas.

PALAVRAS-CHAVE: Manihot esculenta Crantz.; Musa spp.; balanço mineral.

de energia renovável (Rós et al. 2011, Odubanjo et al. 2011).

A determinação do requerimento de nutrientes pelas plantas deve ser feita por meio do conhecimento da curva de crescimento e de absorção de nutrientes pelos órgãos da planta, nas várias fases de desenvolvimento, dentro do ciclo de cultivo. A análise química dos órgãos vegetais é uma ferramenta que permite a avaliação do estado nutricional da planta, identificando a produtividade das culturas, em função

1. Trabalho recebido em mar./2013 e aceito para publicação em jan./2014 (nº registro: PAT 23115).

2. Universidade Federal de Viçosa (UFV), Departamento de Fitotecnia, Viçosa, MG, Brasil.

E-mails: heider.silva@ufv.br, viniciuslopesmelo@yahoo.com.br.

3. Instituto Federal de Educação, Ciência e Tecnologia do Norte de Minas Gerais (IFNMG), Januária, MG, Brasil.

E-mails: ddpacheco.agro@gmail.com,yghomuniz@hotmail.com, hamiltonbioflora@gmail.com. 
do seu estado nutricional (Souza 2007). Além disto, o conhecimento da curva de crescimento fornece importantes dados para a construção de modelos matemáticos para a descrição do crescimento $(\mathrm{Au}-$ gostinho et al. 2008).

A mandioca produz grande quantidade de matéria seca e fresca nas raízes, removendo altas quantidades de nutrientes, quando comparada a outras culturas. A absorção e a distribuição dos nutrientes são altamente relacionadas com a taxa de crescimento das plantas, em função das condições edafoclimáticas e características varietais (Hillocks et al. 2002).

A absorção de nutrientes do solo pela mandioca, em cultivo consorciado, é superior àquela observada em cultivo solteiro, bem como maior que as perdas que ocorrem por erosão e lixiviação. Além disto, a demanda nutricional ocorre de forma particular em cada sistema de consórcio, influenciada pela espécie e densidade de plantio (Leihner 1983).

No município de Januária, norte do Estado de Minas Gerais, a cultura é largamente cultivada (2,5 mil ha), com produção total de 25 mil toneladas ano ${ }^{-1}$, destinada à comercialização in natura ou processada (farinha ou fécula) (IBGE 2010). Na região, a exploração de frutíferas dependentes do uso de irrigação, em especial a bananeira, espécie não tolerante ao déficit hídrico, é uma atividade predominante. Do plantio até a colheita, leva-se, em média, 15 meses, período em que a insolação interna do bananal ainda é alta, já que a primeira planta é menor que as seguintes, e a planta-filha ainda está em fase de crescimento. Neste período, há possibilidade de cultivo de espécies de ciclo curto, como a mandioca, com aproveitamento adicional de recursos energéticos, hídricos e nutricionais (Leihner 1983, Daellenbac et al. 2005). Entretanto, estudos sobre o crescimento e necessidades nutricionais da mandioca em consórcio com a bananeira, em ambiente irrigado, não são conclusivos.

Este estudo objetivou determinar, durante o ciclo da cultura, o acúmulo de matéria seca e micronutrientes, nos diferentes órgãos da planta de mandioca consorciada com bananeira.

\section{MATERIAL E MÉTODOS}

O trabalho foi conduzido de agosto de 2010 a setembro de 2011, na unidade de produção do Instituto Federal de Educação, Ciência e Tecnologia do
Norte de Minas Gerais (IFNMG), em Januária (MG) $\left(15^{\circ} 27^{\prime} \mathrm{S}, 44^{\circ} 22^{\prime} \mathrm{W}\right.$ e altitude de $\left.474 \mathrm{~m}\right)$.

$\mathrm{O}$ solo da área experimental foi classificado como Latossolo Vermelho distrófico e apresentou as seguintes características físicas e químicas, nas amostras da camada $0-20 \mathrm{~cm}$ de profundidade: areia $=$ $75 \mathrm{dag} \mathrm{kg}^{-1} ;$ silte $=14 \mathrm{dag} \mathrm{kg}^{-1} ;$ argila $=11 \mathrm{dag} \mathrm{kg}^{-1}$; $\mathrm{pH}\left(\mathrm{H}_{2} \mathrm{O}\right)=6,5$; matéria orgânica $=0,8 \mathrm{dag} \mathrm{kg}^{-1}$; $\mathrm{P}\left(\right.$ Mehlich-1) $=4 \mathrm{mg} \mathrm{dm}^{-3} ; \mathrm{K}=17 \mathrm{mg} \mathrm{dm}^{-3}$; $\mathrm{Ca}^{2+}=4,1$ mmolc $\mathrm{dm}^{-3} ; \mathrm{Mg}^{2+}=1,2$ mmolc $\mathrm{dm}^{-3}$; $\mathrm{H}+\mathrm{Al}=1,24 \mathrm{mmolc} \mathrm{dm}^{-3} ; \mathrm{Cu}=0,8 \mathrm{mg} \mathrm{dm}^{-3} ; \mathrm{Fe}=$ $27,4 \mathrm{mg} \mathrm{dm}^{-3} ; \mathrm{Mn}=11,3 \mathrm{mg} \mathrm{dm}^{-3} ; \mathrm{e} \mathrm{Zn}=1,7 \mathrm{mg} \mathrm{dm}^{-3}$.

O preparo do solo consistiu de subsolagem, aração, gradagem e abertura mecânica de covas (trado perfuratriz), quando do plantio da bananeira, seguido de abertura de covas com enxada para semeio das manivas de mandioca. O plantio das bananeiras foi realizado utilizando-se mudas de rizoma das variedades Prata Anã, Thap Maeo, Tropical, Caipira, FHIA 1, FHIA 2, FHIA 3, Pacovan Ken, ST 406, PV 4244, PV 4253 e PV 4285, no espaçamento de $3,0 \mathrm{~m} \times 2,5 \mathrm{~m}$.

O plantio da mandioca foi realizado no dia 25/08/2010, quatro meses após o plantio das bananeiras (25/04/2010). Utilizaram-se duas manivas de $10 \mathrm{~cm}$, para cada cova, contendo, em média, 3 a 5 gemas da cultivar Amarelinha. A mandioca foi cultivada no espaçamento de $1,0 \mathrm{~m}$ x 1,0 m (6.666 plantas ha $\left.^{-1}\right)$, com duas fileiras de plantas, entre as fileiras de bananeira.

$\mathrm{Na}$ adubação de plantio da mandioca, foram utilizados $27 \mathrm{~g} \mathrm{cova}^{-1}$ de MAP. A adubação de cobertura foi realizada aos 77 dias após o plantio (DAP), com $18 \mathrm{~g} \mathrm{cova}^{-1}$ de sulfato de amônia e $16 \mathrm{~g} \mathrm{cova}^{-1}$ de cloreto de potássio. A adubação da bananeira foi realizada na cova de plantio (CFSMG 1999).

$\mathrm{O}$ experimento foi delineado em blocos ao acaso, com quatro repetições de $380 \mathrm{~m}^{2}$ cada, compostos de 6 fileiras de $37 \mathrm{~m}$, totalizando 253 plantas. Os tratamentos consistiram de 14 épocas de coleta de plantas $(21 ; 28 ; 35 ; 42 ; 53 ; 70 ; 90 ; 112 ; 142 ; 170$; 202; 234; 269; e 297 DAP), abrangendo os estádios fenológicos da mandioca. Em cada época, foram coletadas, em cada bloco, cinco plantas competitivas, ou seja, ausentes de sintomas visuais de deficiências minerais e doenças, bem como cercadas por plantas adjacentes.

A mandioca foi irrigada até a época da colheita, por meio de sistema de microaspersão que atendia às necessidades hídricas da bananeira. O sistema seguiu 
o arranjo de $6 \mathrm{~m}$ entre as linhas e $5 \mathrm{~m}$ entre os emissores, com vazão de $80 \mathrm{~L} \mathrm{~h}^{-1}$. O controle de plantas daninhas consistiu de capinas manuais realizadas aos 60 e 150 DAP. As pragas e doenças não atingiram níveis de dano que justificassem controle.

As plantas foram separadas em parte área (caules e folhas) e raízes, para determinação da matéria seca. Após a secagem do material vegetal em estufa de ventilação forçada de ar a $65^{\circ} \mathrm{C}$, por 72 horas, este foi moído em moinho tipo Willey, para determinação dos teores de $\mathrm{Cu}, \mathrm{Fe}, \mathrm{Mn}$ e Zn (Malavolta et al. 1997). Os dados dos teores de micronutrientes foram associados aos de matéria seca acumulada na parte aérea e nas raízes, para determinação da quantidade acumulada dos referidos micronutrientes na planta.

Os dados foram submetidos à análise de variância, com o auxílio do software estatístico SAEG 9.1 (SAEG 2007). Os efeitos das épocas de coleta sobre o crescimento e acúmulo de minerais foram avaliados por análise de regressão, utilizando-se o software OriginPro 8.1. Para regressão, os dados foram ajustados ao modelo não linear (sigmoidal) logístico, obedecendo à equação $\mathrm{Y}=\mathrm{a} /\left(1+\mathrm{e}^{-\mathrm{k}(\mathrm{x}-\mathrm{xcc})}\right)$, em que a = máximo valor observado; $\mathrm{e}=$ base do logaritmo neperiano; $\mathrm{k}$ = taxa média de acúmulo ou crescimento; $\mathrm{X}=\mathrm{DAP} ;$ e Xc $=$ dias necessários para atingir metade do crescimento ou o ponto de inflexão.
As taxas de acúmulo de matéria seca e micronutrientes foram obtidas por meio da derivada de primeira ordem da equação, igualada a zero (Moustakas \& Ntzanis 2005, Fernandes et al. 2010). Foram calculados os coeficientes de correlação linear de Pearson entre a produção de matéria fresca das raízes, parte aérea (caule e folha) e planta total e os teores e conteúdos dos micronutrientes.

\section{RESULTADOS E DISCUSSÃO}

O acúmulo de matéria seca pelas raízes seguiu padrão sigmoide, com baixo acúmulo nas épocas iniciais, seguido por rápido incremento $\left(40 \mathrm{~kg} \mathrm{ha}^{-1} \mathrm{dia}^{-1}\right)$, até o final do ciclo, superando a matéria da parte aérea aos 250 DAP (Figura 1a). O máximo acúmulo de matéria seca nas raízes foi de 7.319,22 $\mathrm{kg} \mathrm{ha}^{-1}$, aos 297 DAP. A taxa de acúmulo de matéria seca pelas raízes seguiu padrão distinto do observado para as outras características avaliadas, atingindo maior valor (46,1 $\mathrm{kg} \mathrm{ha}^{-1} \mathrm{dia}^{-1}$ ) aos 208 DAP (Figura 1b).

Em culturas especializadas no acúmulo de reservas nutritivas, os órgãos de reserva, a exemplo das raízes de mandioca, no período de enchimento, são os principais drenos de carboidratos e de nutrientes inorgânicos móveis (Tekalign \& Hammes 2005, Fernandes et al. 2010).

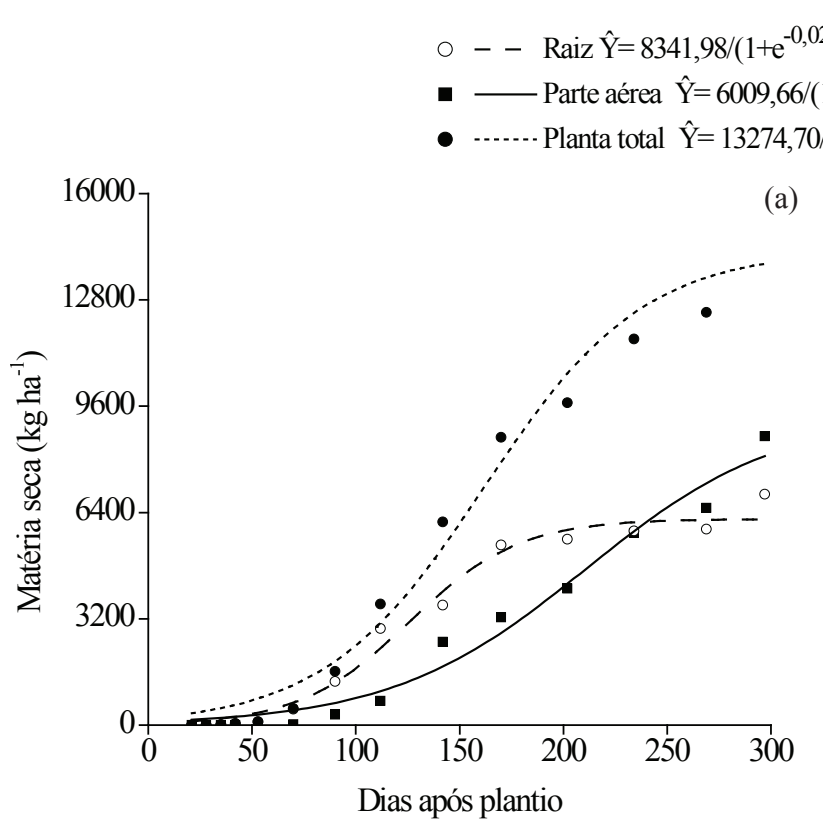

$$
\begin{aligned}
& \left(1+\mathrm{e}^{-0,0375(\mathrm{x}-124,78)}\right) \quad \mathrm{R}^{2}=0,9878^{* * *} \\
& \text { ***** }
\end{aligned}
$$

a)

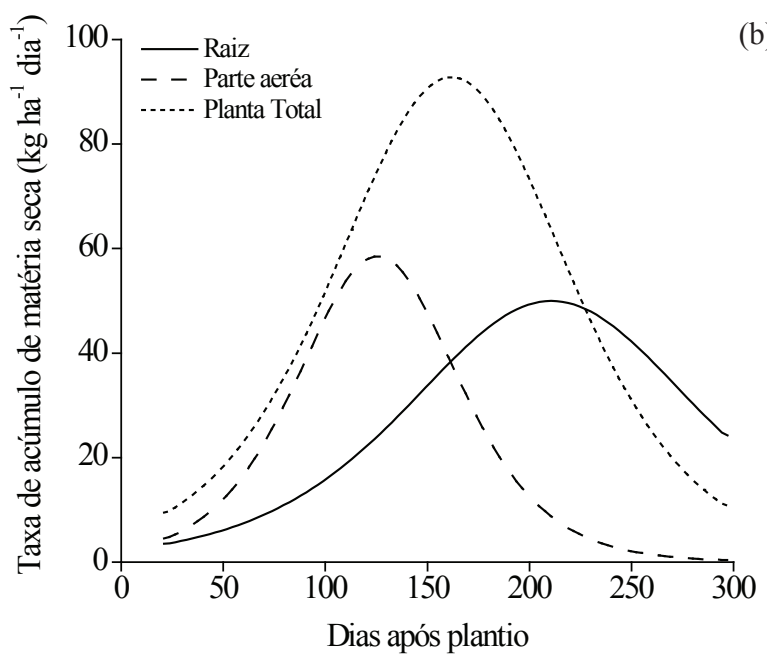

Figura 1. Acúmulo (a) e taxa de acúmulo (b) de matéria seca nas raízes, parte aérea e planta total de mandioca irrigada em consórcio com bananeira, durante o ciclo de cultivo (Januária, MG, 2010-2011). Média de cinco plantas.*** Significativo a 0,1\%, pelo teste F. 
Mesmo com produção de raízes de $18.600 \mathrm{~kg} \mathrm{ha}^{-1}$ de matéria fresca, o padrão de qualidade das raízes (2,79 $\mathrm{kg}$ planta $\left.^{-1}\right)$, em colheita precoce (297 DAP), foi superior ao obtido por Devide et al. (2009), em consórcio orgânico irrigado entre milho e caupi, com rendimento médio de 2,0 $\mathrm{kg}_{\text {planta }}{ }^{-1}\left(33.320 \mathrm{~kg} \mathrm{ha}^{-1}\right)$. Do mesmo modo, esta precocidade de colheita, associada ao cultivo em consórcio irrigado, foi mais eficiente no aumento do rendimento por planta que os resultados encontrados por Albuquerque et al. (2012), na região de Viçosa (MG), com $19.093 \mathrm{~kg} \mathrm{ha}^{-1}$ de matéria fresca de raízes $\left(2,85 \mathrm{~kg}_{\text {planta }}{ }^{-1}\right)$, em cultivo solteiro de mandioca colhida ao 15 meses. Assim, a mandioca cultivada neste sistema de consórcio irrigado apresenta viabilidade econômica, por não afetar o padrão de qualidade comercial das raízes, com a redução no tempo de colheita.

Em trabalho realizado em Correia Pinto (SC), estudando o acúmulo e distribuição de matéria seca em diferentes frações da planta, o acúmulo de matéria seca nas raízes, em duas cultivares de mandioca, também aumentou até o final do ciclo (240 DAP). Ademais, no referido trabalho, foi obtido acúmulo inferior a $300 \mathrm{~g}_{\text {planta }}{ }^{-1}\left(4.752 \mathrm{~kg} \mathrm{ha}^{-1}\right)$ de matéria seca, com maior taxa de acúmulo no período entre 120 e 180 DAP (Sangoi \& Krause 1993), diferentemente da constatação mais tardia (207,95 DAP) desta pesquisa. Em cultivos de 12 meses, os maiores acúmulos de matéria seca ocorrem entre 180 e 300 DAP, época de maior translocação de carboidratos para as raízes (Hillocks et al. 2002, Alves et al. 2006). Estas diferenças relatadas na literatura para o período de acúmulo de matéria seca são justificadas pelo genótipo utilizado e condições edafoclimáticas.

A produção de biomassa de mandioca em condições irrigadas é superior à obtida em cultivo de sequeiro. Embora com grande aumento de matéria na parte vegetativa, incrementos significativos na produtividade de raízes de mandioca, com o uso de irrigação, indicam, assim, grande responsividade da cultura à suplementação hídrica (Odubanjo et al. 2011).

O acúmulo de matéria seca na parte aérea da mandioca, nos períodos iniciais de avaliação, foram maiores, se comparados aos verificados nas raízes (Figura 1a). Contudo, a partir dos 124,78 DAP, a taxa de acúmulo de matéria seca na parte aérea diminuiu, gradativamente, até o final do cultivo. Enquanto aos 170 DAP a parte aérea respondia por $67 \%$ da matéria total da planta, a partir de $250 \mathrm{DAP}$, verificou-se maior matéria para as raízes do que para a parte aérea (Figura 1a). O acúmulo máximo de matéria seca na parte aérea foi de $6.000 \mathrm{~kg} \mathrm{ha}^{-1}$, obtido ao final do ciclo (Figura 1a).

A maior taxa de acúmulo de matéria seca na parte aérea ocorreu anteriormente à observada nas raízes, sendo que, nas avaliações iniciais, a taxa foi duas vezes inferior no órgão subterrâneo (Figura 1b). $\mathrm{O}$ máximo valor na parte aérea $\left(56 \mathrm{~kg} \mathrm{ha}^{-1} \mathrm{dia}^{-1}\right)$ foi estimado aos $125 \mathrm{DAP}$, revelando que a planta direciona a produção de fotoassimilados, nos períodos iniciais, para a formação da parte aérea, para, em seguida, deslocar os mesmos para os órgãos de reserva (Leihner 1983, Hillocks et al. 2002, El-Sharkawy 2004).

A taxa de acúmulo diário de matéria seca na parte aérea da mandioca foi menor ao final do ciclo, com estimativa de apenas $5 \%$ de ganho, a partir de 210 DAP. Este padrão está associado, principalmente, com a senescência e abscisão das folhas observadas no intervalo (Sangoi \& Krause 1993). Deste modo, para garantir maior produtividade da cultura, é fundamental associar a precocidade de tempo necessário para atingir máximo índice de área foliar com o aumento na longevidade da atividade fotossintética (Pereira \& Machado 1987).

De maneira geral, o acúmulo de matéria seca total na mandioca também aumentou com padrão sigmoidal, caracterizado por três fases bem definidas (Figura 1a). Na primeira fase (21 a 90 DAP), o crescimento foi lento, com acúmulo máximo de apenas $14 \%$ da matéria seca total. A segunda fase de crescimento foi intensificada, com acúmulo máximo de $68 \%$, no período de 90 a 220 DAP, e, ao final ( 220 a 297 DAP), constou de acúmulo equivalente a 18\% da matéria total.

O máximo acúmulo de matéria seca total foi obtido ao final do ciclo, com valor de $12.936 \mathrm{~kg} \mathrm{ha}^{-1}$ (Figura 1a). A maior taxa de acúmulo diário, obtida no ponto de inflexão da curva de crescimento, revelou que a época de máximo crescimento da planta ocorreu aos 159,49 DAP (Figura 1b). Embora a quantidade acumulada de matéria seca total seja inferior à obtida por Odubanjo et al. (2011), em condições irrigadas, ressalta-se que o estudo foi conduzido em cultivo solteiro, propiciando altos valores de produção de biomassa vegetal.

Em sistema de cultivo consorciado, a mandioca é submetida a diferentes graus de sombreamento e intensidade luminosa, durante os primeiros meses de cultivo (Alves et al. 2006). No entanto, as culturas 
frequentemente consorciadas com a mandioca são de ciclo menor, exercendo efeito apenas nos períodos iniciais. Porém, neste trabalho, a cultura consorciada foi de maior ciclo e grande porte, limitando a incidência de radiação solar, principalmente ao final do cultivo, que coincide com o estádio de tuberização das raízes e reduz a fotossíntese líquida (Hillocks et al. 2002).

A curva de acúmulo de $\mathrm{Cu}$ nas raízes também seguiu padrão de crescimento sigmoide semelhante à da matéria seca, até o final do cultivo, com intensificação a partir dos 115 DAP (Figura 2a). O máximo acúmulo de $\mathrm{Cu}$ foi de $69 \mathrm{~g} \mathrm{ha}^{-1}$, obtido ao final do ciclo de cultivo.

A taxa máxima de acúmulo diário de $\mathrm{Cu}$ nas raízes (206,17 DAP) ocorreu mais tardiamente que a observada na parte aérea (125,74 DAP) (Figura 2b). $\mathrm{O}$ crescente acúmulo de $\mathrm{Cu}$ nos órgão de reserva é explicado pela baixa mobilidade deste nos vegetais superiores, sendo sua taxa de retranslocação induzida pela senescência foliar, que é dependente da atividade fotossintética das folhas (Kirkby \& Römheld 2007). Assim, o $\mathrm{Cu}$ é translocado prioritariamente para os tecidos fotossintetizantes, sendo retranslocado para as raízes em maior quantidade apenas após o processo de senescência foliar.

A taxa de acúmulo de $\mathrm{Cu}$ na parte aérea foi superior à das raízes até 170 DAP. A partir de então, observou-se priorização do acúmulo deste nutriente nas raízes (Figura 2a). Aos 175 DAP, o valor de $\mathrm{Cu}$ correspondia a $85,6 \%$ do máximo estimado para a parte aérea, indicando que, após este período, a alocação deste nutriente praticamente cessou, no referido órgão. $\mathrm{O}$ valor máximo acumulado deste micronutriente na parte aérea foi de $74,41 \mathrm{~g} \mathrm{ha}^{-1}$, obtido ao final do cultivo. $\mathrm{O} \mathrm{Cu}$ é um elemento regulatório da atividade enzimática nos processos fotossintéticos e respiratórios dos tecidos aéreos, explicando, assim, o maior acúmulo do nutriente nesse órgão da planta, especialmente nos períodos inicias de cultivo (Kirkby \& Römheld 2007).

A quantidade total de $\mathrm{Cu}$ acumulada foi de $139 \mathrm{~g} \mathrm{ha}^{-1}$, obtida aos 297 DAP. Pela derivada de primeira ordem da equação, que descreve o acúmulo de Cu na planta total, aos 152,55 DAP, ocorreu o valor máximo de acúmulo diário $\left(1,0 \mathrm{~g} \mathrm{ha}^{-1}\right)$. Ao final do cultivo, a quantidade acumulada de $\mathrm{Cu}$ nas raízes respondia por quase metade do total acumulado na planta. O mesmo comportamento no padrão de distribuição do referido micronutriente foi observado por Howeler \& Cadavid (1983), que relataram quantidade superior de $\mathrm{Cu}$ na parte aérea até os 8 meses de cultivo, e, a partir de então, maior acúmulo nas raízes.

O padrão de acúmulo de Fe foi semelhante nas raízes e na parte aérea, no período de 21 a 120 DAP

$$
\begin{aligned}
& \text { - Raiz } \hat{\mathrm{Y}}=78,75 /\left(1+\mathrm{e}^{-0,0223(\mathrm{x}-206,17)}\right) \mathrm{R}^{2}=0,9762^{* * *} \\
& \text { - - Parte aérea } \hat{\mathrm{Y}}=74,56 /\left(1+\mathrm{e}^{-0,0362(\mathrm{x}-125,74)}\right) \mathrm{R}^{2}=0,9794^{* * *} \\
& \text { - -...-. Planta total } \hat{\mathrm{Y}}=141,14 /\left(1+\mathrm{e}^{-0,0283(\mathrm{x}-152,55)}\right) \mathrm{R}^{2}=0,9833^{* * *}
\end{aligned}
$$
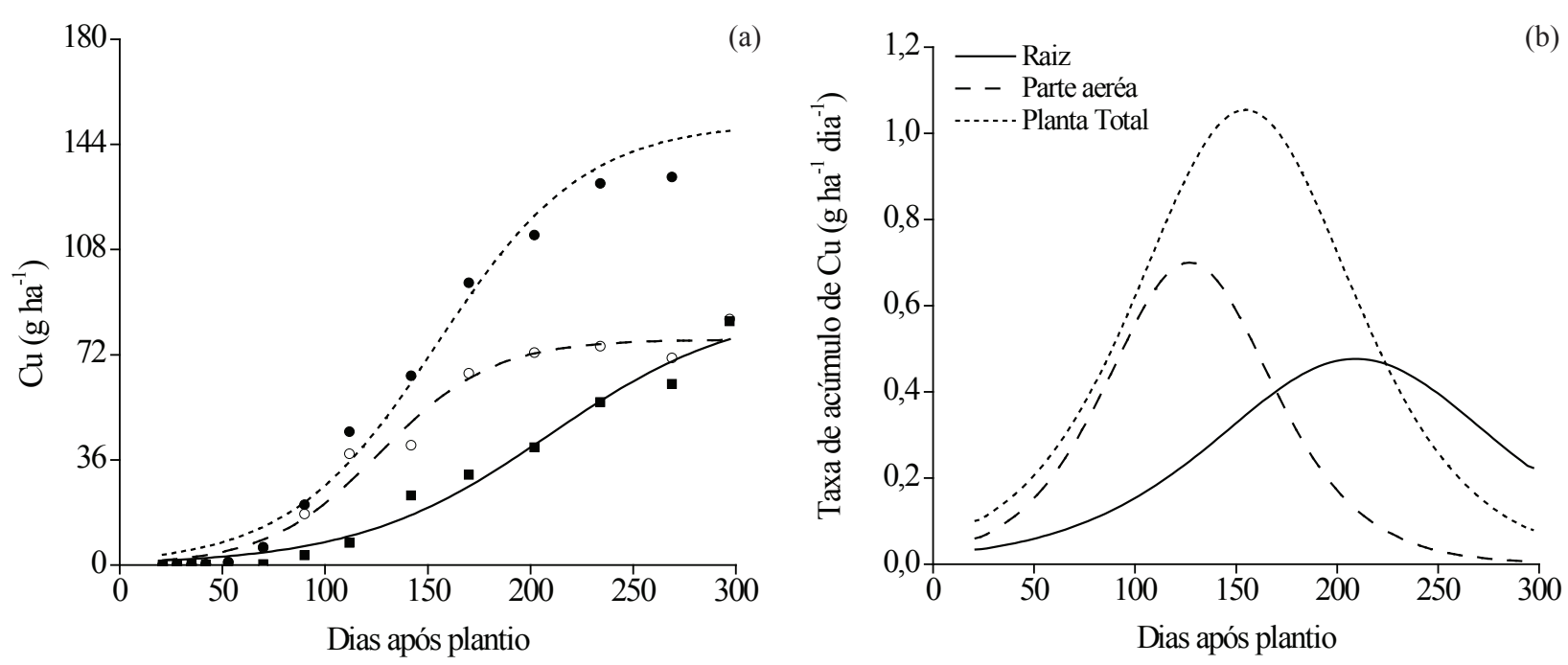

Figura 2. Acúmulo (a) e taxa de acúmulo (b) de Cu pelas raízes, parte aérea e planta total de mandioca irrigada em consórcio com bananeira, durante o ciclo de cultivo (Januária, MG, 2010-2011). Média de cinco plantas. ${ }^{* * *}$ Significativo a $0,1 \%$, pelo teste F. 
(Figura 3a). Em seguida, a maior quantidade deste nutriente foi acumulada pelas raízes, ao passo que, na parte aérea, a partir de então, a planta acumulou apenas $15 \%$ de Fe no caule e folhas.

Nas raízes, aos 121,62 DAP, foi estimado o maior acúmulo diário de $\mathrm{Fe}\left(11 \mathrm{~g} \mathrm{ha}^{-1} \mathrm{dia}^{-1}\right)$ (Figura 3b) e, na parte aérea, a maior taxa ocorreu aos 101,03 DAP $\left(8,9 \mathrm{~g} \mathrm{ha}^{-1} \mathrm{dia}^{-1}\right)$. O acúmulo de $\mathrm{Fe}$, mais tardio ou mais precoce, nas partes da planta se explica pela variação de sua necessidade metabólica, nas fases de desenvolvimento da cultura. Ao final do ciclo de cultivo, as plantas de mandioca acumularam $1.408 \mathrm{~g} \mathrm{ha}^{-1} \mathrm{de} \mathrm{Fe}$, sendo $63 \%$ referentes à quantidade acumulada pelas raízes e $37 \%$ da parte aérea (Figura 3a).

As curvas de acúmulo de Mn nas raízes e na parte aérea foram distintas, estando este nutriente concentrado, principalmente, na segunda estrutura (Figura 4a). Nas raízes, o Mn seguiu padrão sigmoidal de acúmulo, com baixos valores dos 21 aos 115 DAP, quando registraram-se apenas 2,8\% e $15,8 \%$ do total, respectivamente. Entretanto, na parte aérea, no mesmo período, o acúmulo de Mn foi maior, alcançando $81 \%$ de Mn do total, aos 115 DAP.

Aos 297 DAP, as raízes acumularam $49 \mathrm{~g} \mathrm{ha}^{-1}$ de Mn (Figura 4a), enquanto, na parte aérea, a quantidade foi de $143 \mathrm{~g} \mathrm{ha}^{-1}$. A maior taxa de acúmulo de $\mathrm{Mn}$ nas raízes foi alcançada mais tardiamente (167,25 DAP) que na parte aérea (94,33 DAP)
(Figura 4b). Desta maneira, o Mn absorvido pela planta, nos primeiros meses, é preferencialmente reportado para a parte aérea, para atuação nos processos fotossintéticos da planta (Marschner 1995, Taiz \& Zeiger 2005). As plantas de mandioca, ao final do ciclo de cultivo, acumularam $182 \mathrm{~g} \mathrm{ha}^{-1} \mathrm{de} \mathrm{Mn}$.

Howeler \& Cadavid (1983) verificaram acúmulo de Mn inferior ao encontrado nesta pesquisa, atestando, inclusive, diminuição de sua quantidade, ao final do ciclo de cultivo. Constataram acentuada variação no teor do nutriente ao longo do crescimento da mandioca, confirmando o relato de Mukhopadhyay \& Sharma (1991), sobre a abundante flutuação nutricional para $\mathrm{Mn}$, nos tecidos das plantas. A absorção de Mn é pouco controlada pela planta, refletindo, muitas vezes, em discrepância entre o teor encontrado nos tecidos vegetais e a quantidade requerida, o que pode induzir deficiência ou acúmulo do nutriente acima da necessidade metabólica (Clarkson 1988).

$\mathrm{O}$ acúmulo de $\mathrm{Zn}$ foi intenso na parte aérea e lento nas raízes, no período de 21 a 130 DAP (Figura 5a). O acúmulo nas raízes, ao final do cultivo, foi de $99 \mathrm{~g} \mathrm{ha}^{-1}$, com taxa máxima ocorrendo aos 192,98 DAP $\left(0,61 \mathrm{~g} \mathrm{ha}^{-1}\right)$ (Figura 5b). Na parte aérea, a quantidade máxima acumulada foi de $137 \mathrm{~g} \mathrm{ha}^{-1} \mathrm{dia}^{-1}$, sendo o valor máximo de acúmulo diário da ordem de 1,8 $\mathrm{g} \mathrm{ha}^{-1} \mathrm{dia}^{-1}$, obtido aos 100,84 DAP.

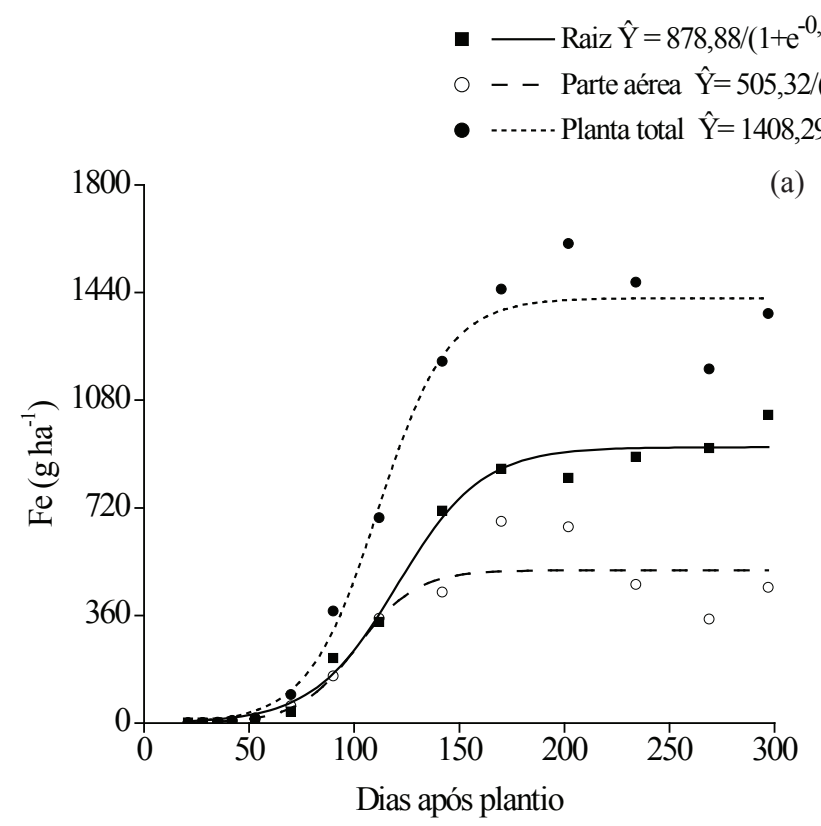

Figura 3. Acúmulo (a) e taxa de acúmulo (b) de Fe pelas raízes, parte aérea e planta total de mandioca irrigada em consórcio com bananeira, durante o ciclo de cultivo (Januária, MG, 2010-2011). Média de cinco plantas. ${ }^{* * *}$ Significativo a $0,1 \%$, pelo teste F. 

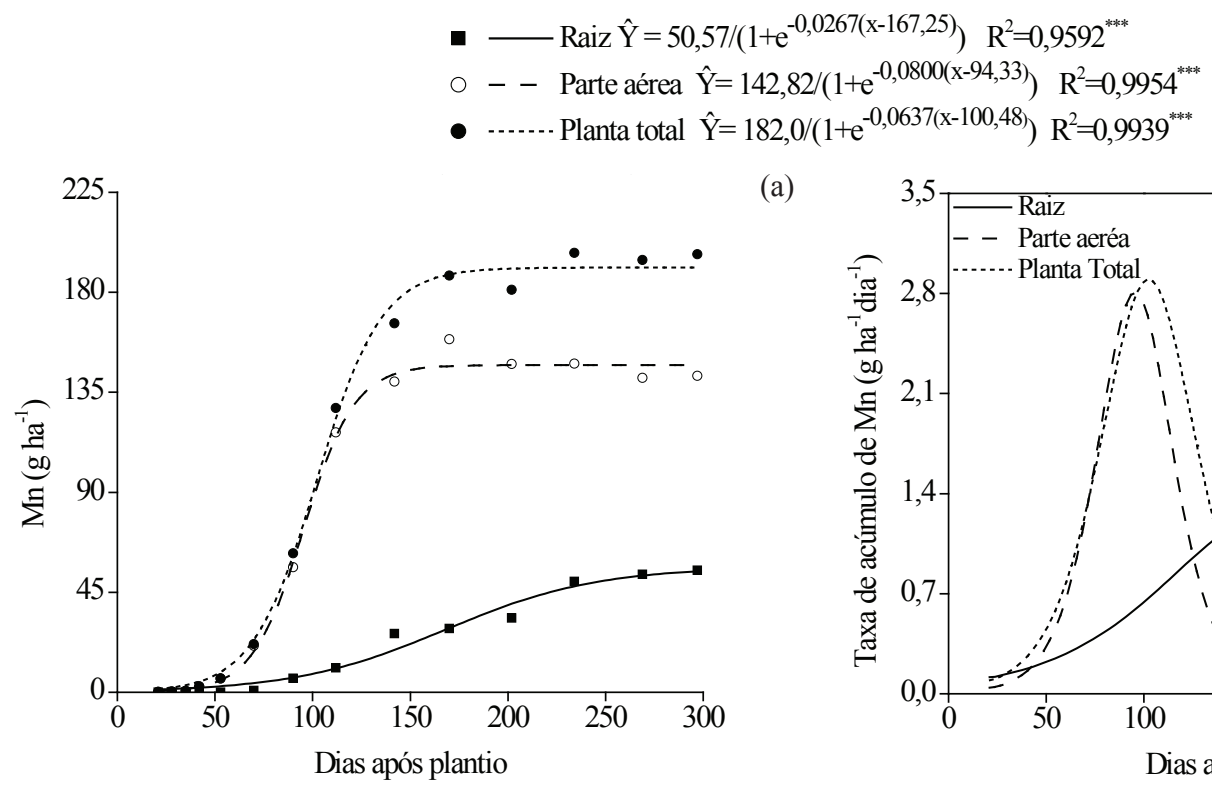

(a)

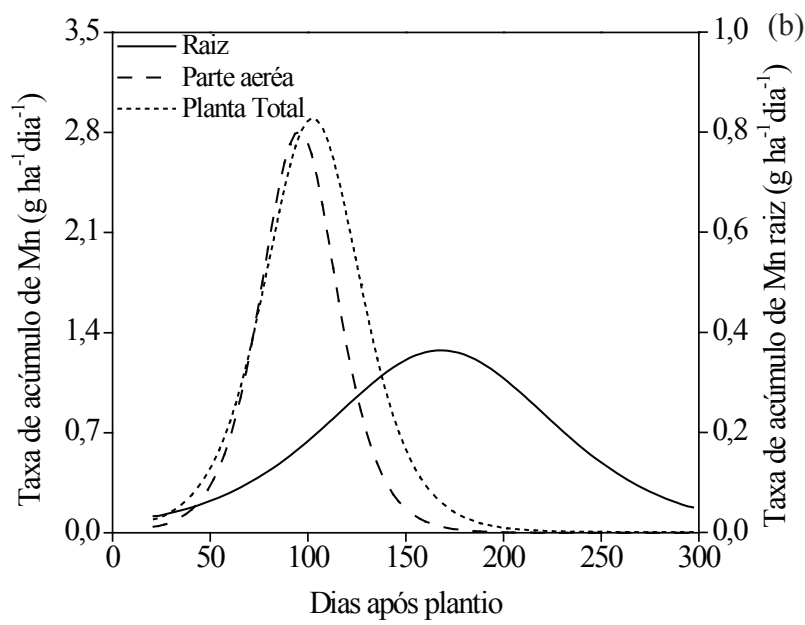

Figura 4. Acúmulo (a) e taxa de acúmulo (b) de Mn pelas raízes, parte aérea e planta total de mandioca irrigada em consórcio com bananeira, durante o ciclo de cultivo (Januária, MG, 2010-2011). Média de cinco plantas. ${ }^{* * *}$ Significativo a $0,1 \%$, pelo teste F.

$$
\begin{aligned}
& \text { - - Raiz } \hat{\mathrm{Y}}=107,83 /\left(1+\mathrm{e}^{-0,0228(\mathrm{x}-192,98)}\right) \mathrm{R}^{2}=0,9695^{* * *} \\
& \text { ○ - - Parte aérea } \hat{\mathrm{Y}}=137,02 /\left(1+\mathrm{e}^{-0,0523(\mathrm{x}-100,84)}\right) \quad \mathrm{R}^{2}=0,9797^{* * *} \\
& \text { - -..... Planta total } \hat{\mathrm{Y}}=225,02 /\left(1+\mathrm{e}^{-0,0342(\mathrm{x}-124,69)}\right) \mathrm{R}^{2}=0,9785^{* * *}
\end{aligned}
$$
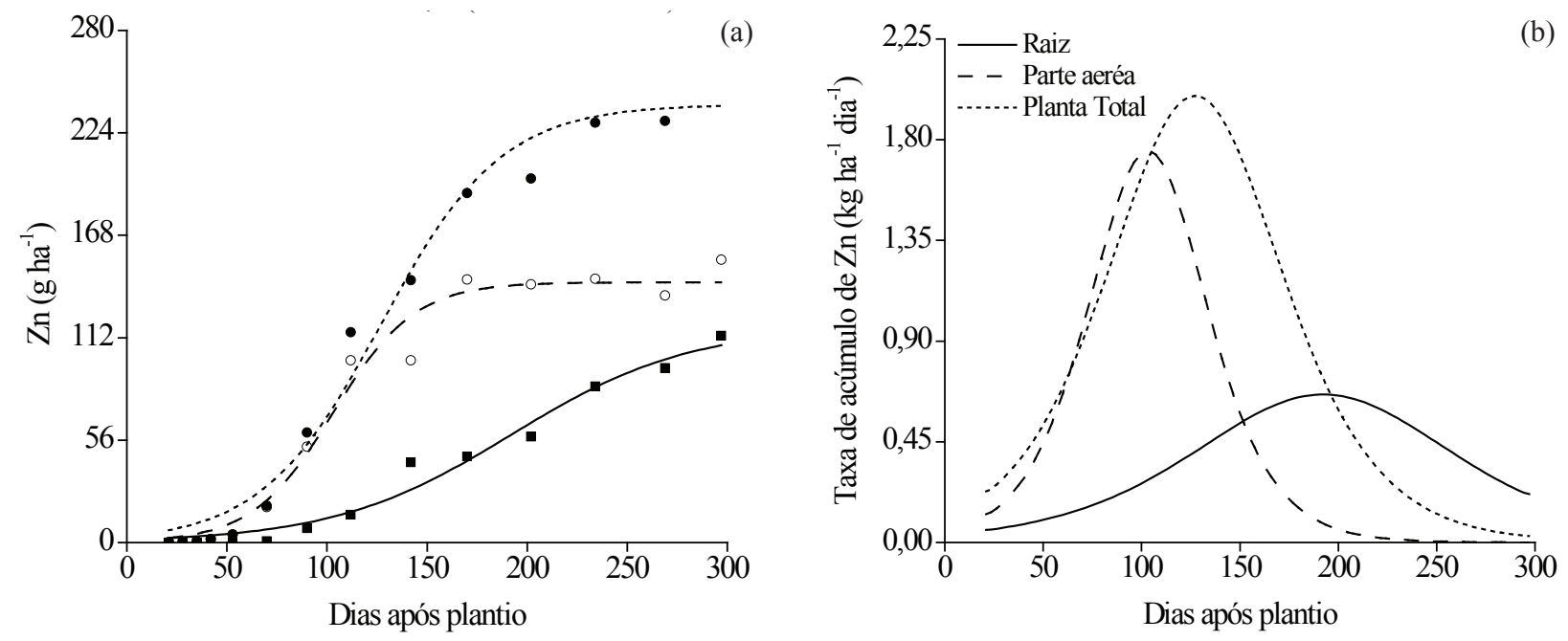

Figura 5. Acúmulo (a) e taxa de acúmulo (b) de Zn pelas raízes, parte aérea e planta total de mandioca irrigada em consórcio bananeira, durante o ciclo de cultivo (Januária, MG, 2010-2011). Média de cinco plantas. ${ }^{* * *}$ Significativo a $0,1 \%$, pelo teste F.

O Zn é um elemento de baixa concentração em grande parte dos solos, se comparado à quantidade requerida pelos vegetais, de modo que o contato com as raízes, para a sua absorção, ocorre, principalmente, via difusão (Kirkby \& Römheld 2007). Assim, o alto teor de água no solo, condicionado pelo uso de irrigação, provavelmente favoreceu o transporte do elemento no solo, justificando o seu acúmulo contínuo pelas raízes de mandioca.

Os teores de micronutrientes se correlacionaram negativamente com o acúmulo de matéria seca na parte aérea, nas raízes e em toda a planta de mandioca, 
exceto para o $\mathrm{Cu}$. Os teores de $\mathrm{Cu}, \mathrm{Fe}, \mathrm{Mn}$ e $\mathrm{Zn}$ se correlacionaram significativamente com a produção de matéria seca da planta, indicando aumento na produtividade, com o acúmulo de micronutrientes. Dentre estes, para o $\mathrm{Cu}$, observou-se maior coeficiente de correlação com a produção de matéria seca pela planta, tanto no órgão de reserva $(\mathrm{r}=1,000)$ quanto na parte aérea $(\mathrm{r}=0,9981)$ e planta total $(\mathrm{r}=0,9984)$, sendo os ajustes de regressão lineares positivos para todas as situações de estudo entre matérias secas.

$\mathrm{O} \mathrm{Cu}$ é componente de diversas proteínas atuantes nos processos fotossintéticos e respiratórios, como a plastocianina, essencial no transporte de elétrons (Kirkby \& Römheld 2007). Assim, maiores taxas de fixação de $\mathrm{CO}_{2} \mathrm{e}$, consequentemente, produção de matéria seca possuem alta correlação com a atividade da proteína contendo $\mathrm{Cu}$, justificando a correlação positiva do nutriente.

\section{CONCLUSÕES}

1. A mandioca em consórcio alcançou alta produtividade de raízes por planta, em colheita precoce, mantendo excelente padrão comercial.

2. A mandioca de mesa (cultivar Amarelinha), em consórcio com bananeira, durante a maior parte do ciclo de cultivo, acumulou maior quantidade de matéria seca na parte aérea, com posterior retranslocação ao final, para a formação das raízes.

3. $\mathrm{O}$ acúmulo de micronutrientes pelas plantas de mandioca obedeceu à seguinte ordem: $\mathrm{Fe}>\mathrm{Zn}>$ $\mathrm{Mn}>\mathrm{Cu}$.

\section{REFERÊNCIAS}

ALVES, A. A. C. et al. Fisiologia da mandioca. In: EMPRESA BRASILEIRA DE PESQUISA AGROPECUÁRIA(Embrapa). Aspectos socioeconômicos e agronomicos da mandioca. Cruz das Almas: Embrapa Mandioca e Fruticultura Tropical, 2006. p. 138-169.

ALBUQUERQUE, J. de A. de et al. Cultivo de mandioca e feijão em sistemas consorciados realizado em Coimbra, Minas Gerais, Brasil. Revista Ciência Agronômica, Fortaleza, v. 43, n. 3, p. 532-538, 2012.

AUGOSTINHO, L. M. D. et al. Acúmulo de matéria seca e marcha de absorção de nutrientes em mudas de goiabeira 'Pedro Sato'. Bragantia, Campinas, v. 67, n. 3, p. $577-585,2008$.

CLARKSON, D. T. The uptake and translocation of manganese by plant roots. In: GRAHAM, R. D.;
HANNAM, R. J.; UREN, N. C. Manganese in soils and plants. Dordrecht: Kluwer Academic Publishers, 1988. p. 101-111.

COMISSÃO DE FERTILIDADE DO SOLO DO ESTADO DE MINAS GERAIS (CFSMG). Recomendação para o uso de corretivos e fertilizantes em Minas Gerais: $5^{\text {a }}$ aproximação. Viçosa: CFSMG, 1999.

DAELLENBACH, G. C. et al. Plant productivity in cassava-based mixed cropping systems in Colombian hillside farms. Agriculture, Ecosystems and Environment, Zürich, v. 105, n. 4, p. 595-614, 2005.

DEVIDE, A. C. P. et al. Produtividade de raízes de mandioca consorciada com milho e caupi em sistema orgânico. Bragantia, Campinas, v. 68, n. 1, p. 145-153, 2009.

EL-SHARKAWY, M. A. Cassava biology and physiology. Plant Molecular Biology, Dordrecht, v. 56, n. 1, p. 481501, 2004.

FERNANDES, A. M. et al. Crescimento, acúmulo e distribuição de matéria seca em cultivares de batata na safra de inverno. Pesquisa Agropecuária Brasileira, Brasília, DF, v. 45, n. 8, p. 826-835, 2010.

HILLOCKS, R. J.; THRESH, J. M.; BELLOTTI, A. C. Cassava: biology, production, and utilization. London: CABI Publishing, 2002.

HOWELER, R. H.; CADAVID, L. F. Accumulation and distribution of dry matter and nutrients during a 12-month growth cycle of cassava. Field Crops Research, Amsterdam, v. 7, n. 2, p. 123-139, 1983.

INSTITUTO BRASILEIRO DE GEOGRAFIA E ESTATÍSTICA(IBGE). Produção agrícola 2010: Sistema IBGE de Recuperação Automática - SIDRA. 2010. Disponível em: <http:www.sidra.ibge.gov.br/bda/agric/>. Acesso em: 25 set. 2012.

KIRKBY, E. A.; RÖMHELD, V. Micronutrientes na fisiologia de plantas: funções, absorção e mobilidade. Piracicaba: International Plant Nutrition Institute, 2007. (Encarte técnico informações agronômicas,18).

LEIHNER, D. Management and evaluation of intercropping systems with cassava. Cali: Centro Internacional de Agricultura Tropical, 1983.

MALAVOLTA, E.; VITTI, G. C.; OLIVEIRA, S. A. Avaliação do estado nutricional das plantas: princípios e aplicações. 2. ed. Piracicaba: Potafos, 1997.

MARSCHNER, H. Mineral nutrition of higher plants. 2. ed. London: London Academic Press, 1995.

MOUSTAKASA, N. K.; NTZANISB, H. Dry matter accumulation and nutrient uptake in flue-cured tobacco (Nicotiana tabacum L.). Field Crops Research, Amsterdam, v. 94, n. 1, p. 1-13, 2005. 
MUKHOPADHYAY, M. J.; SHARMA, A. Manganese in cell metabolism of higher plants. Botanical Review, Bronx, v. 57, n. 2, p. 117-149, 1991.

ODUBANJO, O. O.; OLUFAYO, A. A.; OGUNTUNGE, P. G. Water use, growth, and yield of drip irrigated cassava in a humid tropical environment. Soil and Water Research, Praha, v. 6, n. 1, p. 10-20, 2011.

PEREIRA, A. R.; MACHADO, E. C. Análise quantitativa do crescimento de comunidades vegetais. Campinas: Instituto Agronômico, 1987. (Boletim técnico, 114).

RÓS, A. B. et al. Crescimento, fenologia e produtividade de cultivares de mandioca. Pesquisa Agropecuária Tropical, Goiânia, v. 41, n. 4, p. 552-558, 2011.

SAEG: sistema para análises estatísticas. Versão 9.1. Viçosa: Fundação Arthur Bernardes, 2007.
SANGOI, L.; KRAUSE, N. D. Acúmulo e distribuição de matéria seca em diferentes frações da planta de mandioca no planalto catarinense. Pesquisa Agropecuária Brasileira, Brasília, DF, v. 28, n. 10, p. 1151-1164, 1993.

SOUZA, F. V. de. Curva de crescimento e exportação de nutrientes e sódio por frutos de mangueira Palmer, Haden e Tommy Atkins. 2007. 54 f. Dissertação (Mestrado em Ciência do Solo) - Universidade Estadual Paulista, Jaboticabal, 2007.

TAIZ, L.; ZEIGER, E. Plant physiology. 2. ed. Sunderland: Sinauer Associates Inc. Publishers, 2005.

TEKALIGN, T.; HAMMES, P. S. Growth and productivity of potato as influenced by cultivar and reproductive growth: I. Stomatal conductance, rate of transpiration, net photosynthesis, and dry matter production and allocation. Scientia Horticulturae, Amsterdam, v. 105, n. 1, p. 13-27, 2005. 